\title{
Perancangan User Interface Sistem Informasi Penjualan dan Promosi Jamur Berbasis web Pada CV. Branding Padang
}

\author{
Arman $^{1}$, Keukeu Rohendi' ${ }^{2}$, Nelfira ${ }^{3}$, Eri Tanjung ${ }^{4}$ \\ ${ }^{1,2,3,4}$ STMIK Indonesia Padang \\ Sistem Informasi STMIK Indonesia Padang \\ Jln. Khatib Sulaiman Dalam No.1 Padang, telp. 07517056199 \\ 19arman@stmikindonesia.ac.id, ${ }^{2}$ keukeurohendi@ stmikindonesia.ac.id, \\ ${ }^{3}$ nelfira@stmikindonesia.ac.id, ${ }^{4}$ eritanjung@gmail.com
}

\begin{abstract}
Abstrak
Kemajuan teknologi informasi sudah diiringi dengan perkembangan TI dan perkembangan alat telekomunikasi dan layanan internet dalam kehidupan masyarakat. Semua unser sudah saling mendukung satu sama lain, sehingga dapat melahirkan konsepkonsep baru dalam kehidupan sehari-hari. Tujuannya adalah agar masyarakat dapat mendapatkan informasi tentang produk/ barang dan jasa yang di hasilkan oleh suatu perusahan dengan menggunakan sarana TI. Beberapa perusahan yang sudah penggunakan TI seperti UKM, UMKM maupun industri rumahan. CV. Branding salah satu UMK (Usaha Kecil Menengah) yang berada di kota padang yang belum menggunakan sarana TI, baik dalam penjualan, pemasaran dan media promosi. Sehingga dengan belum menggunakan sarana TI dapat berdampak kepada CV tersebut, seperti turunnya omset penjualan jamur, pelanggannya masih sedikit, jangkauan pemasaran masih minin. Dengan adanya masalah tersebut peneliti mencarikan solusinya dengan membangun aplikasi Sistem Informasi Penjualan dan Promosi Jamur berbasis Web. Dalam membangun aplikasi ini peneliti menggunakan metode penelitian model waterfall, alat bantu perancangan sistem yang digunakan adalah model UML. Hasil penelitian ini adalah dengan adanya aplikasi ini Penjualan jamur dan promosi berbasis web ini jamur yang diproduksi oleh $\mathrm{CV}$. Branding dapat dipasarkan secara online, meningkatnya jumlah pelanggan, selain itu juga dapat meningkatkan omset penjualan jamur setiap saat dari sebelumnya.
\end{abstract}

Kata kunci: sistem, informasi, penjualan, promosi, berbasis online

\begin{abstract}
The development of information technology accompanied by the development of the internet supports each other, thus giving birth to the concept of internet-based information technology that we often hear berbasi online. CV. Padang Branding is one of the UMK (Small and Medium Enterprises) in the city of Padang that has not used the internet facilities, both in sales and in the promotion of the products it produces. So that it has an impact on the CV, such as the decline in mushroom sales turnover produced, the customers are still small, and the marketing range is not wide. With the problems faced by $C V$. The branding of the researcher provides a solution so that the problems that occur can be overcome by designing a User Interface Information System for Sales and Promotion of Mushrooms on the CV. Web-based Padang Branding. The research method used in designing applications using waterfal and system design tools using UML. Results achieved with the existence of this application Mushroom sales have used applications both in sales, orders, and also in promotions already carried out online and from the sale of mushrooms can be increased from before.
\end{abstract}

Keywords: system, information, sales, promotions, online based 


\section{PENDAHULUAN}

Sekarang ini perkembangan teknologi sudah semakin maju perkembangannya, sekarang ini sudah hampir semua segi kehidupan menggunakan teknologi [1]. Dengan adanya perkembangan TI tersebut dapat memberikan manfaat bagi semua orang, sebab teknologi yang diciptakan tersebut tujuannya untuk meringankan beban pekerjaan manusia sehari-hari, selain itu juga dapat membantu manusia dalam memberikan informasi yang cepat, tepat, akurat, tentang suatu perusahaan atau instansi yang kita butuhkan [2]. Selain itu sarana TI juga dapat dimanfaatkan sebagai wadah untuk kegiatan bisnis [3] dengan membangun sebuah aplikasi website. Dengan adanya website kita dapat melakukan berbagai kegiatan seperti, transaksi [4], pemesanan [5], penjualan [6] promosi produk yang dihasilan oleh perusahan, baik itu UKM, UMKM dan industri rumahan seperti berbagai macam barang, cendara mata, asesoris / kerajinan tangan [7] hingga makanan, jamur, minuman, dan sebagainya. Sebelum mengenal adanya teknologi internet para penjual pembeli, transaksi menggunakan media promosi, pemasaran perusahaan secara convesional seperti dari mulut ke mulut, penyebaran brosur, poster, radio, surat kabar sehingga sedikit orang yang mengenalnya. Dengan adanya kehadiran internet ditengan masyarakat saat ini, kita dapat melakukan bisnis lebih mudah dan lebih cepat.

CV. Branding padang adalah salah satu usaha industri rumahan yang bergerak dalam usaha budi daya jamur tiram yang sudah banyak menghasilkan jamur tiram, CV. Tersebut berada di baypas Kec. Koto Tangah, Kota Kota Padang, Sumbar. CV. Branding bergerak dibidang kuliner budi daya jamur tiram. Produk rumahan ini menghasilkan jamur tiram. Awalnya $\mathrm{CV}$. Branding hanya melayani pemesanan dalam area perumahan dan warga sekitarnya. Seiring dengan berjalannya waktu, CV. Branding juga mengalami perkembangan sampai sekarang ini. Dalam menjalankan usaha bisnis jamur ritam ini CV. Tersebut banyak terjadi masalah yang dihadapinya, dintaranya adalah $\mathrm{CV}$. Branding padang belum memiliki sarana TI dalam penjualan, pemasaran maupun media promosi, sehingga pelanggan harus datang ketempat lokasi untuk melakukan pembelian jamur. Selain itu pelanggan dari CV. Branding hanya penduduk sekitar saja, untuk promosi jamur tersebut dijual di warung-warung sekitar yang diantar lansung oleh CV tersebut setiap hari. Selain itu pelanggan yang ada dari luar daerah tidak mengetahui keberadaan dan produk jamur tersebut.

Oleh karena itu agar permasalah yang dihadapi oleh CV. Branding ini dapat dicarikan solusinya dengan merancang suatu aplikasi penjualan dan promosi berbasis web yang bertujuan untuk mempermudah proses penjualan dan promosi produk yang diprodiksi oleh CV. tersebut. Sekarang ini website sudah banyak dilakukan untuk menunjang semua kegiatan pada semua produk secara online [8], seperti penjualan produk, promosi, pemesanan dan transaksi dari sebuah perusahaan.

\section{TINJAUAN PUSTAKA}

\section{a. Perancangan}

Design menurut Jogiyanto H.M, 2005 [9], menjelaskan bahwa: "Desain menggambarkan elemen-elemen dari langkah kajian pada struktur dimana pada elemen penyusunan dari struktur dapat menjelaskan suatu rangkaian sistem yang akan dilakukan sebelum dilaksanakan aturan kedalam sebuah program.

\section{b. Sistem Informasi}

Adalah gabungan dari teknologi TI dengan kegiatan user sama pengguna dengan harapan dapat membantu semua pekerjaan dalam manajemen pada suatu organisasi [10]. Jadi informasi merupakan suatu fakta yang diselesaikan menjadi kerangka menjadi bermanfaat buat user atau penggunanya. Jadi fakta yang sudah dikerjakan saja belum cukup untuk dikatakan sebagai sebuah informasi. Agar bahan bisa sebagai suatu informasi, fakta yang ada terlebih dahulu harus diproses, setelah diproses baru dapat di 
gunakan oleh pengguna sesuai dengan kebutuhan mereka masing-masing, baik instansi pemerintah, swasta dan perorangan.

\section{c. Pengertian Penjualan}

Merupakan suatu kegiatan atau aktifitas yang dilakukan oleh dua orang antara sipenjual dan sipembeli dalam bisnis yang menjual barang atau benda. Didalam proses penjualan ini memberikan pemindahan kepemilikan barang atau jasa kepada pembeli sesuai dengan harga yang sudah mereka sepakati kedua bela pihak, dengan harapan kedua bela pihak dapat mendapatkan suatu keuntungan atau laba darihasil transaksi yang dikerjakan pada suatu kegiatan [11]. Transaksi merupakan suatu kegiatan perusahaan yang menyebabkan peralihan terhadap kondisi asset keuangan sebuah perusahaan, contohnya penjualan, pembelian, pembayaran gaji setiap saat, serta pembayaran berbagai macam biaya operasional lainnnya setiap saat.

\section{d. Promosi}

Promosi adalah suatu kegiatan yang dilakukan oleh suatu perusahaan untuk pemberitahuan kepada masyarakat luas tentang suatu barang atau produk yang di jual, dengan tujuan untuk menarik calon konsumen atau pelanggan untuk membeli dan menggunakan produk yang meraka jual. Dengan adanya promosi ini dapat meningkatkan omset penjualan dari perusahan atau distributor dari sebelumnya. Untuk media yang digunakan dalam promosi ini perusahan menggunakan berbagai media seperti, koran, TV, media masa, brosur, poster, radio dan media lainnya [12].

\section{e. Pegertian Website}

Website adalah suatu gabungan dari beberapa halaman yang memunculkan beraneka ragam jenis informasi baik dalam bentuk teks, gambar diam ataupun bergerak, video dan suara, maupun kombinasi dari semuanya, baik dalam bentuk keadaan diam maupun dalam keadaan bergerak. Dimana membuat suatu elemen struktur yang sama-sama berkaitan dimana tiap-tiap berkaitan dengan jejaring dengan bagian yang lain [6].

\section{f. Database}

Database merupakan sebuah fakta yang sudah diperoleh sebelumnya, database juga sering disebut basis data. Sebuah data atau fakta dapat ditemukan informasi yang dapat diperoleh dan dicatat, sedangkan basis merupakan tempat untuk berkumpul. Jadi basis data adalah kumpulan fakta yang diperoleh dan untuk berikutnya disimpan dalam suatu tempat dalam komputer, seperti media penyimpanan antara lain hardis, flesdis, memory dan sejenisnya [13]. Manfaat Basis data salah satu adalah dapat mengatasi problem pada sebuah aplikasi yang memakai media berbasis berkas, sehingga untuk memproses basis data yang ada dapat gunakan berupa software peranti lunak yang disebut dengan DBMS.

\section{g. MysQL}

MySQL merupakan objek peranti lunak dalam sistem manajemen pada basis data. DBMS yang aktual. MYSQL merupakan implementasi dari sistem manajemen basis data relasional yang disebar luaskan secara gratis dibawah lisensi GPL. Dan juga merupakan Aplikasi yang dipakai untuk server dalam database, diman fungsi server itu sendiri dapat melakukan pengiriman dan penerima data yang sudah dikirim secara langsung dan sifatnya multi user dan menggunakan instruksi baku dari SQL [14].

\section{METODE PENELITIAN}

Dalam meleksanakan kegiatan penelitian ini, peneliti memakai model metode penelitin pendekatan Web engineering, metode ini adalah melaksanakan penerapan web yang mengabungkan rekayasa piranti lunak. Metode ini lebih memfokuskan pada teori 
cara pelaksanaan kegiatan dan tatakelolah tentang aplikasi sudah dibangun. Adapun tujuan dari Aplikasi yang akan dikembangkan untuk mewakilkan aplikasi yang lama secara utuh yang telah berjalan. Adapun langkah dari Web engineering adalah sebagai berikut [15] :

a. Komunikasi pelanggan

Komunikasi adalah isi dari bisnis, komunikasi pelanggan ini dikerjakan agar komunikasi lebih tertarik untuk membeli barang yang sudah mereka beli sebelumnya. Indivising dari pemasaran dapat meningkatkan penjualan kepada konsumen. Dimana marketing akan menjual barang yang di jualnya memiliki kualitas bagus dan tahan lama dan sebagainya, sehingga pelanggan dapat tertarik untuk membeli barang yang dijualnya. Jadi pada komunikasi pada pelanggan ini ada dua yaitu analisa tentang bisnis dan perumusan permasalahan. Analisa bisnis pendefenisian hal-hal yang berkaitan dengan jalannya aplikasi web, seperti, pengguna sistem, pengolahan data, relasi data antara web dengan basis data yang butuhkan sesuai dengan kebutuhan. Sedangkan Perumusan yaitu pengabungan informasi tentang bahan yang akan buat dalam aplikasi web tersebut.

b. Perancangan

Pada tahap merupakan langkah pembuatan rancangan awal dari desain program yang akan dibangun yang terdiri dari beberapa komponen yang terpisah dalam kompulan yang utuh, dan berguna sebagai desain sistemdigambarkan dalam bentuk bagan aliran sistem, ditampilkan dalam bentuk grafik.

c. Pemodelan

Pada tahap merupakan rancana deskripsi singkat yang dapat menjelaskan suatu objek, teori, yang sering berupa penyederhaaan atau identitas, yang berupa model fisik dari rancangan atau bisa juga dalam bentuk protoype sesuai dengan aplikasi yang akan di bangun.

d. Kontruksi

Merupakan suatu kegiatan yang dikerjakan untuk membangun suatu aplikasi baik dalam bentuk sarana maupun dalam bentuk fisik. Seperti fisik yang digunakan agar aplikasi dapat berjalan dengan baik. Kemudian membangun struktur program yang berkaitan dengan input, proses dan ouputnya. Selain itu yang tidak kala penting adalah teknologi yang dipakai apakah sudah mendukung jalannya aplikasinya dan dibarengi dengan perkembangan teknologi dengan program bantu untuk pengembangan aplikasi untuk masa yang akan datang.

\section{e. Deployment}

Aplikasi web di rancang dapat digunakan untuk kebutuhan user dalam membantu pekerjaan, dipakai oleh pengguna, selain itu juga dapat digunakan untuk perbaikan ataupun perbaharuan terhadap sistem sesuai dengan masukan dan saran dari penilaian selama pengguna mengoperasikan aplikasi tersebut. tujuannya adalah sebagai masukan kepada sipengembang untuk dilakukan perobahan, modifikasi terhadap aplikasi web yang sudah diciptakan dengan alasan untuk peningkatan mutuh dari aplikasi yang sudah dirancang tersebut agar lebih baik dari sebelumnya.

\section{HASIL DAN PEMBAHASAN}

Website yang dirancang itu tujuannya adalah untuk mempermudah user intecase pada pihak management $c v$. Bdanding dalam proses penjualan dan promosi jamur terhadap pelanggan yang akan melakukan pembelian dan menjual produk jamur yang mereka 
produksi selama ini, selain itu juga mempermudah konsumen dalam memesan produk tanpa harus datang ke lokasinya. Dalam perancangan user interface aplikasi web ini, perangkat keras yang digunakan adalah laptop Core i3, RAM dua Gb, Harddisk 500 GB, dan perangkat hardware dan software pendukung lannya.

a. Hasil dari perancangan user interface adalah sebagai berikut :

1. Menu pengunjung

Halaman ini dapat melihatkan desain dasar dari bahagian sub menu dari program yang digunakan oleh pengunjung yang ada mengakses aplikasi ini. Sebagai tampilan untuk pengunjung dari program aplikasi Penjualan jamur online dengan metode uniterval. Menu ini dirancang untuk memudahkan pengunjung dalam melakukan proses pemilihan jamur, pencarian jenis jamur dan pemesanan jamur secara online. Di dalam halaman pengunjung ini terdapat sub-sub halaman menu. Pengunjung juga bisa melakukan pencarian data produk. Agar lebih jelasnya dapat dilihat pada Gambar 1.

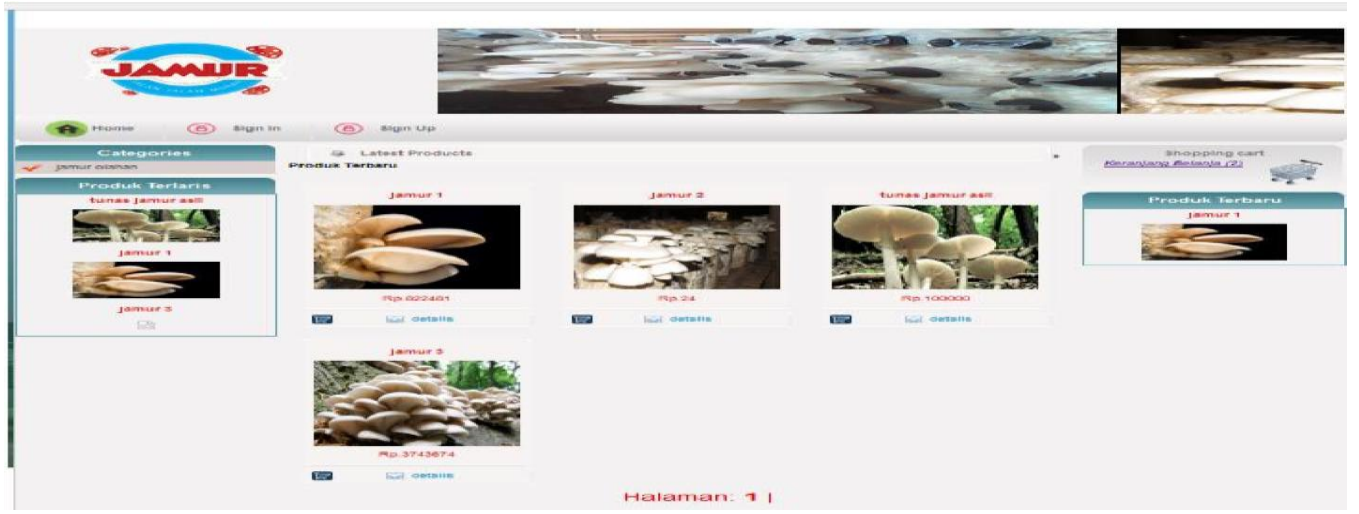

Gambar 1. Halaman Home Pelanggan

2. Halaman Menu Profil

Merupakan menu untuk menampilkan informasi tentang profile toko jamur online kepada pengunjung baru maupun member dapat mengetahui keberadaan lokasi toko jamur online. Dalam proses pembeli jamur ini pelanggan CV. Branding tidak perlu datang ke lokasi lagi dengan alasan pelanggan takut kena tindak penipuan. Untuk lebih lanjut dapat dilihat pada Gambar 2. 


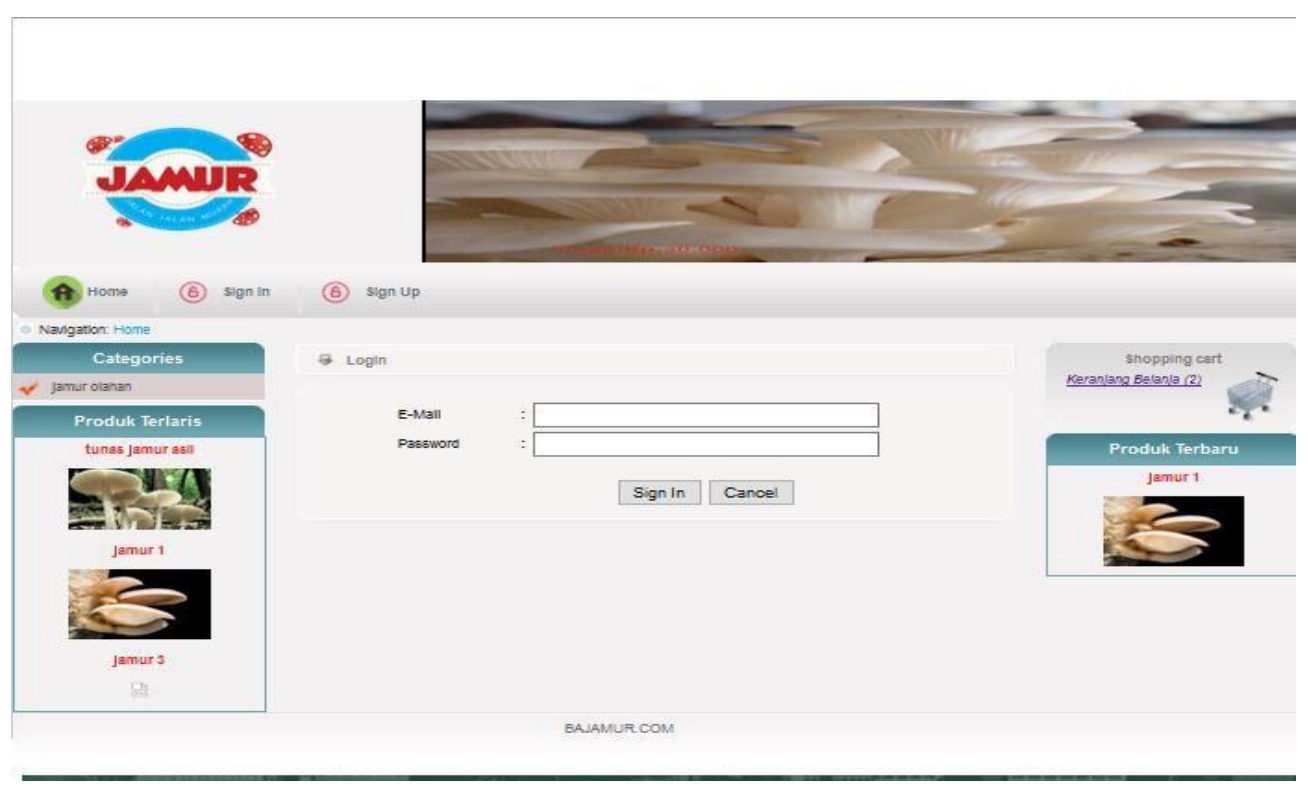

Gambar 2. Halaman Menu Profil

\section{Halaman Menu Panduan}

Menu panduan merupakan mеnu untuk menampilkan informasi panduan cara pembelian produk pada aplikasi penjualan jamur online dengan metode intervall. Halaman ini berfungsi agar setiap pengunjung yang ingin membeli produk tidak mengalami kesulitan dalam memesan jamur, karena dalam sistem sudah ada panduan untuk menjalankan sistem tersebut atau cara pemesanan secara detail mulai dari pemilihan jamur sampai pelanggan melakukan transaksi pembelian. Untuk langkah lebih lanjut dapat dilihat pada Gambar 3.

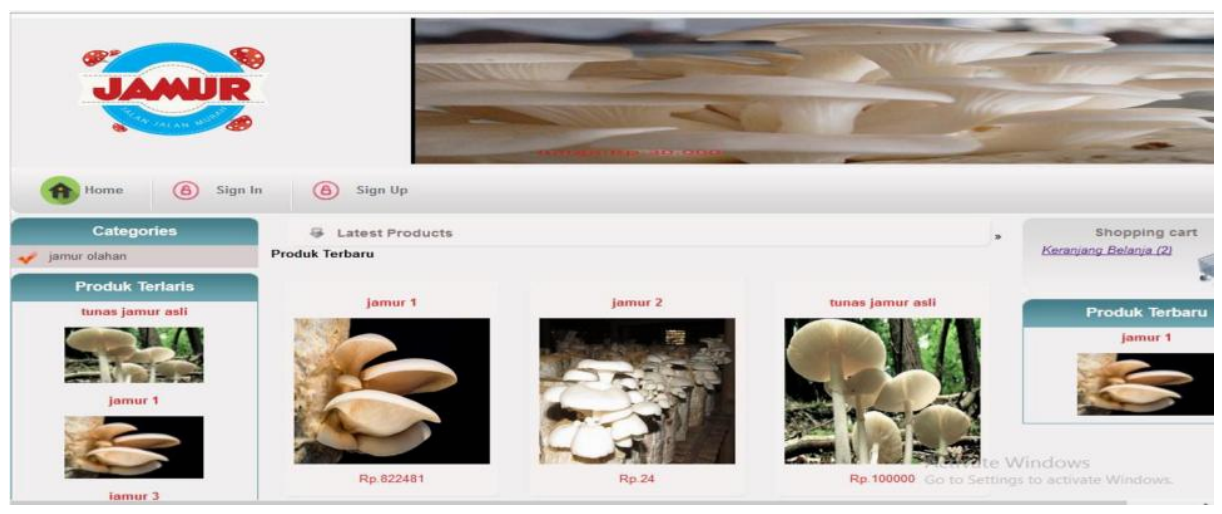

Gambar 3. Halaman Menu Panduan

\section{Halaman Input Pendaftaran Pelanggan}

Pada home pelanggan ini memliki sebuah input yaitu input pelanggan baru atau pendafataran pelanggan baru yang bertujuan untuk input pendaftaran pelanggan untuk bisa mendapatkan hak akses untuk login agar bisa melakukan pemesanan jamur yang dibutuhkan dan form pendaftaran pelanggan ini adalah merupakan langkah pertama untuk bisa mengakses system, dengan menunggu validasi dari admin. Sepeti pada Gambar 4. 


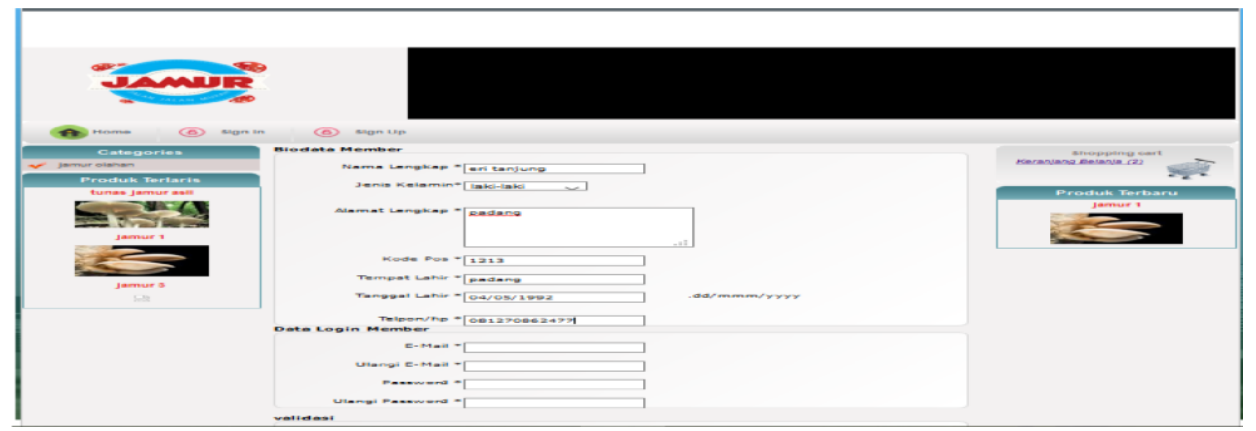

Gambar 4. Pendaftaran Pelanggan Baru

5. Halaman Menu Keranjang Belanja

Merupakan menu untuk menampilkan daftar keranjang belanja yang dipesan setelah pengunjung melakukan pemilihan jamur produk jamur maka pengunjung dapat menekan tombol simpan konfirmasi pesanan tersebut agar pesanan. Untuk langkah selanjutnya dapat dilihat pada Gambar 5.

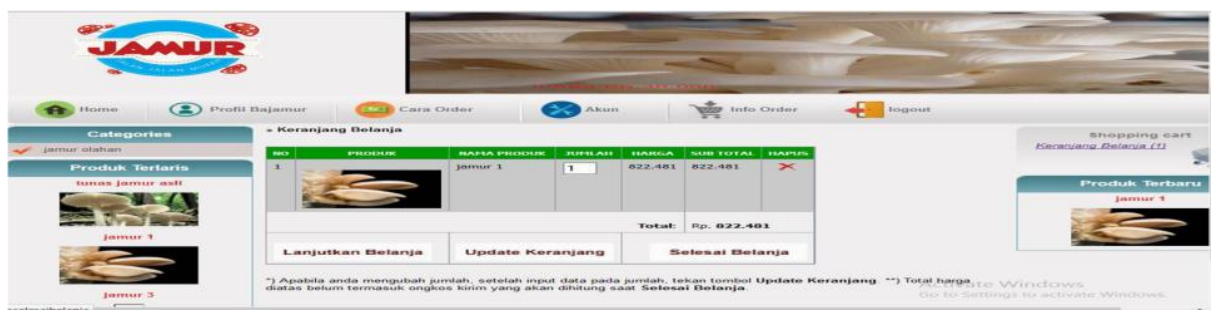

Gambar 5. Halaman Keranjang Belanja

6. Halaman menu Daftar Pesanan

Untuk sebagai bukti pesanan, pengunjung dapat mencetak bukti pemesanan pada halaman daftar pesanan. tombol cetak yang berfungsi untuk mencetak bukti pemesanan sebagai bukti pemesanan. Untuk lebih lanjut dapat dilihat pada Gambar 6.

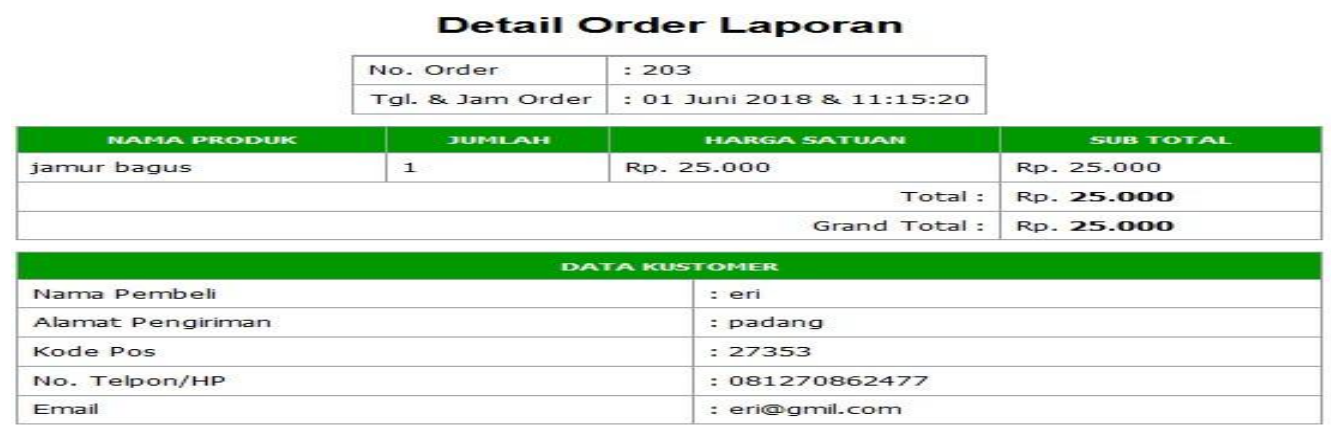

Gambar 6. Bukti Pemesanan

7. Berikutnya Halaman Menu Daftar Pesanan Jamur

Pada halaman menu ini menampilkan daftar pelanggan yang melakukan pemesanan yang tujuannya untuk daftar pesanan dapat dengan cepat diketahui. Pada halaman menu ini, admin bisa mencetak faktur pesanan sebagai bukti pemesanan jamur yang nantinya akan dicocokkan dengan bukti pemesanan pelanggan. Faktur pesanan pelanggan tersebut 
dapat dicetak dengan cara menekan tombol cetak yang ada pada halaman daftar pesanan tersebut. Untuk lebih lanjutnya dapat dilihat pada Gambar 7.
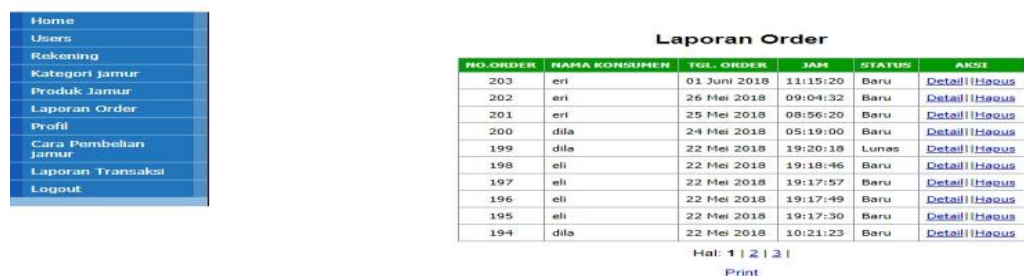

\section{Gambar 7. Halaman Daftar Pemesanan}

\section{KESIMPULAN}

Berdasarkan penjelasan dari bab-bab sebelumnya, maka dapat diambil kesimpulan sebagai berikut :

a. Degan adanya aplikasi berbasi Web yang sudah rancang ini, semoga dapat memperluas pasar dari penjualan dan promosi jamur tiram pada CV. Branding Padang tersebut.

b. Sistem berbasis web ini sudah dapat pakai oleh calon pelanggan CV. Tersebut secara online dan dapat diakses kapan dan dimana saja pelenggan berada dan pelanggan dapat melakukan pembelian dan melihat informasi tentang jamur yang diproduksi oleh CV.Branding Padang tersebut dimana saja pelanggan berada.

c. Dapat membantu para admin dan menejer dalam mengatur kegiatan baik dalam mengolah produksi jamur, pemesanan secara online, pengiriman jamur. Selain itu juga mempermudah dalam membuat laporan rugi laba setiap priode.

d. Aplikasi Web dibangun ini mempermudah pelanggan dalam melakukan pemesanan produk.

\section{UCAPAN TERIMAKASIH}

Berisi ucapan terima kasih kepada lembaga LPPM STMIK Indonesia Padang dan juga kepada Pimpinan CV. Branding Padang yang telah membantu dalam pelaksanaan penelitian tersebut.

\section{Daftar Pustaka}

[1] A. Muhson, "Staf Pengajar Jurusan Pendidikan Ekonomi - Universitas Negeri Yogyakarta 1," J. Pendidik. Akunt. Indones., vol. VIII, no. 2, 2010.

[2] T. Purnamasari, "Pembangunan Sistem Informasi Pengolahan Data Pegawai Dan Penggajian Pada Unit Pelaksana Teknis Taman Kanak-Kanak Dan Sekolah Dasar Kecamatan Pringkuku," J. Speed - Sentra Penelit. Eng. dan Edukasi, vol. 5, no. 2, pp. 1-6, 2013.

[3] V. M. M. Siregar, "Perancangan Website Sebagai Media Promosi Dan Penjualan Produk," TAM (Technology Accept. Model., vol. 9, no. 1, pp. 15-21, 2018.

[4] S. Kosasi, "Pro s id in g SNATIF Ke-1 Ta hun 201 4," Pembuatan Sist. Inf. Penjualan Berbas. Web Untuk Memperluas Pangsapasar, pp. 225-232, 2014.

[5] H. T. Fristanto, "Pembuatan Website Promosi Dan Pemesanan Produk Pada Home Industri Agro Santoso Jamur Punung Pacitan,” Indones. J. Netw. Secur., vol. 3, no. 3, pp. 58-62, 2014.

[6] S. Handayani, "Perancangan Sistem Informasi Penjualan Berbasis E-Commerce Studi Kasus Toko Kun Jakarta," Ilk. J. Ilm., vol. 10, no. 2, p. 182, 2018.

[7] M. Widyasuti, A. Wanto, D. Hartama, and E. Purwanto, "Rekomendasi Penjualan Aksesoris Handphone Menggunakan Metode AHP" KOMIK (Konferensi Nas. Teknol. Inf. dan Komputer), vol. I, pp. 27-32, 2017. 
[8] I. Sidharta and B. Suzanto, "Pengaruh Kepuasan Transaksi Online Shopping Dan Kepercayaan Konsumen Terhadap Sikap Serta Perilaku Konsumen Pada E-Commerce," J. Comput. Bisnis, Vol. 9, No. 1, Juni 2015, 23-36 ISSN 2442-4943, vol. 9, no. 1, pp. 23-36, 2015.

[9] S. Bakti, N. A. Hasibuan, L. T. Sianturi, and R. D. Sianturi, "Perancangan Aplikasi pembelajaran Coreldraw X3 Menggunakan Metode Web Based Learning," J. Ris. Komput. (JURIKOM), Vol. 3 No. 4, Agustus 2016 ISSN 2407-389X, vol. 3, no. 4, pp. 32-35, 2016.

[10] J. Ekonomi, D. A. N. Teknik, and I. Vol, “ISSN : 2338-4697 e-ISSN : 2579-3322," vol. 5, no. 2, pp. 7-18, 2017.

[11] Y. A. Badii and D. Kuncoro, "Perancangan Sistem Informasi Penjualan Dan Bembelian Serta Pengendalian Stok Barang Pada Toko Batik Kusumawardani Solo,” vol. 23, no. 1, pp. 19-26, 2017.

[12] D. A. N. Informasi, "Perancangan Website Sebagai Media Promosi," vol. 3, no. 1, pp. 8286, 2018.

[13] J. J. Click et al., "Perancangan Sistem Informasi Delivery Order Pupuk Merk Trubus Berbasis Web Pada CV. Prabu Siliwangi Padang," J. J-CLICK, vol. 5, no. 1, pp. 98-106.

[14] A. Cipta, D. Surakarta, J. Ahmad, and Y. No, "Pemanfaatan database Mysql Untuk Proses Komputerisasi Peminjaman Dan Pengembalian alat Laboratorium Di SMK SMK Binawiyata Sragen," J. IT CIDA, vol. 2, no. 1, pp. 67-73, 2016.

[15] A. H. Marlinda Linda, "Sistem Informasi Budi Daya Jamur Menggunakan Metode Web Engineering," Semin. Nas. Sains dan Teknol., vol. 1, no. 3, pp. 1-4, 2015. 